\title{
Effects of Aging Temperature, Time, and Pre-Strain on Mechanical Properties of AA7075
}

\author{
Suleyman Kilic ${ }^{a}$ (D, Ilyas Kacar ${ }^{b}$, Mevlut Sahin $^{c}$, Fahrettin Ozturk ${ }^{d, e}$, Oguz Erdem $^{a}$ \\ ${ }^{a}$ Department of Mechanical Engineering, Ahi Evran University, Kirsehir 40200, Turkey \\ ${ }^{b}$ Department of Mechatronics Engineering, Niğde Ömer Halisdemir University, Nigde 51240, Turkey \\ ${ }^{c}$ Technical Sciences Vocational School, Niğde Ömer Halisdemir University, Nigde 51240, Turkey \\ ${ }^{d}$ Strategy and Technology Management, Turkish Aerospace Industries, Inc., Ankara 06980, Turkey \\ eDepartment of Mechanical Engineering, Ankara Ylldirm Beyazıt University, Ankara 06010, Turkey
}

Received: January 03, 2019; Revised: June 18, 2019; Accepted: July 17, 2019

Aluminum alloys of the 7xxx series (AA7075) are preferred in the aerospace and automotive industries due to their low densities, high strength, good corrosion resistance properties. Additionally, these alloys show the most effective aging properties among aluminum alloys. For this reason, it is very important to determine the most appropriate aging parameters for microstructural development. Literature review reveals that the effect of pre-strain on springback has not been studied yet. In this study, the effects of aging temperature, time, and pre-strain on mechanical properties are investigated for AA7075. Precipitates present in solid solutions of AA7075 and their effects are examined. Results reveal that $M g Z n_{2}$ precipitation is not observed at aging temperatures of 120 and $160{ }^{\circ} \mathrm{C}$. After the formation of $\mathrm{MgZn}_{2}$ precipitates, microstructure becomes softer when aging continues at a higher temperature or longer period of time. It is clearly seen that pre-strain causes Portevin-Le Chatelier (PLC) effect after aging at 120 and $160^{\circ} \mathrm{C}$ for aging times of 30 and 90 minutes.

Keywords: $7 X X X, A A 7075$, aging; pre-strain, mechanical properties, springback.

\section{Introduction}

Aluminum alloys have specific characteristics depending on their chemical composition. AA 7075 alloys consists of $\mathrm{Zn}, \mathrm{Mg}$ and $\mathrm{Cu}$ elements particularly in addition to main Al matrix. They change microstructure and give specific features effecting manufacturing processes to be applied on. Also AA7075 is very sensitive to heat treatments.

Aluminum alloys of the 7XXX series (AA7XXX) have been widely used in the aerospace industry due to their low densitiles, high strength, fracture toughness, and resistance to stress corrosion cracking ${ }^{1-3}$. Phases in these alloys' microstructures are key factors affecting their performance. Based on alloying elements, $\eta\left(\mathrm{MgZn}_{2}\right)$, $T\left(\mathrm{Al}_{2} \mathrm{CuMg}\right)$, and $S\left(\mathrm{Al}_{2} \mathrm{CuMg}\right)$ phases are observed as secondary phases in $7 \mathrm{XXX}$ series of Al-Zn-Mg-Cu alloy ${ }^{4-8}$.
The $M g Z n_{2}$ phase observed in AA7075 is widely effective in deformation by formations of small precipitates in microstructure ${ }^{9} . \eta$ " and $\eta$ ' are metastable (or non-equilibrium) transition precipitates with their own distinct crystal structure, while $\eta$ is the equilibrium stable precipitate of $M g Z n_{2}$ settled in grain boundaries ${ }^{10}$. While the $T\left(\mathrm{Al}_{2} \mathrm{Mg}_{3} \mathrm{Zn}_{3}\right)$ phase forms at lower $\mathrm{Zn}$ : $\mathrm{Mg}$ ratio, the hexagonal $\eta$ ' phase may form at higher $\mathrm{Zn}$ : $\mathrm{Mg}$ ratio in the aging process at high temperatures. These phases are formed by two consecutive steps. First, a transformation process leads a solid solution to supersaturated GP nucleus (Guinier-Preston zones). Later, GP nucleus becomes phases by following either $\eta$ ' $\rightarrow \eta$ or T' $\rightarrow$ T reactions ${ }^{1}$. Both steps can be done either naturally by long periods of time called "natural aging" or by means of a temperature-controlled process named "artificial aging". An aging process and phase transitions are illustrated in Fig. 1.

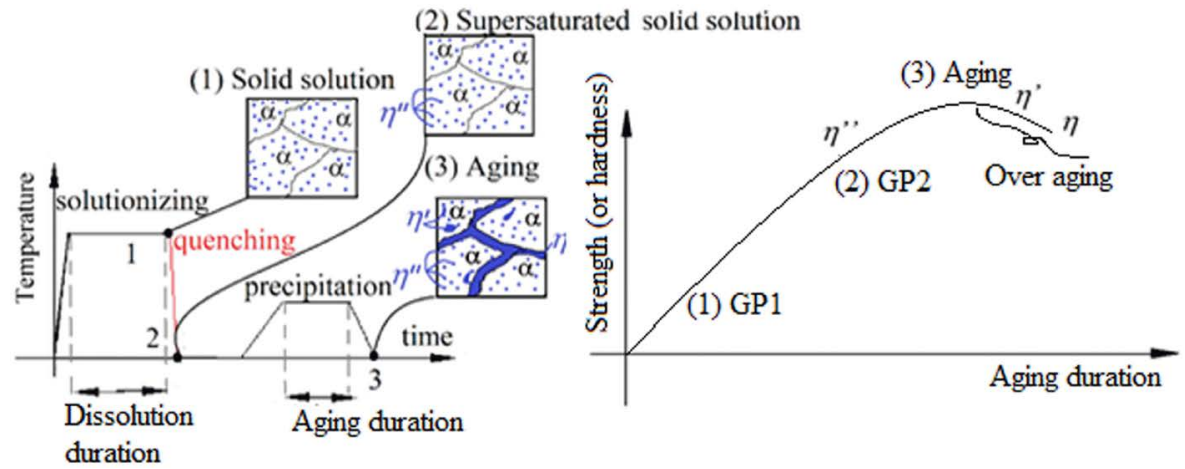

Figure 1. Sub steps of the aging process and phase transitions with respect to aging time 
Fig. 1 indicates the stages of the aging process ofAA7075. It consists of "dissolution, cooling, and precipitation" steps. In Fig. 1, "dissolution" is seen at point 1 where precipitates are dissolved inside the grains under control of high temperature. At the end of this stage, all the effects of present heat treatments (if any) are eliminated. For example, when AA7075 T6 is dissolved, just AA7075 is obtained. Aging is sensitive to cooling rate named quenching. In "precipitation" stage, aging is carried out during one- or two-, or three-step re-aging treatments.

AA7075 has good aging capability ${ }^{11,12}$. From past to present, many studies have been performed to improve the aging properties of AA $7075^{13-19}$. It is seen that many different combinations of "temperature \& duration" have been tested for artificial aging ${ }^{20}$. T6 tempering (aging at $120^{\circ} \mathrm{C}$ for 24 hours) is widely recommended ${ }^{12}$. Aluminum alloys of the 7XXX series are aged by following some artificial aging steps. First of all, the nucleation of GP regions requires several hours at $107-120$ ${ }^{\circ} \mathrm{C}$. The second stage is formations of $M g Z n_{2}$ precipitations at $160170{ }^{\circ} \mathrm{C}$. The formation of these precipitate particles causes about $15 \%$ decrease in strength when compared to the T6 heat treatment ${ }^{21}$. As the aging time increases, the precipitates grow and start to prevent dislocation movements and cause an increase in strength. If the precipitate size exceeds the critical value, on the contrary, it makes the dislocation movements easy and causes a decrease in strength. It is seen that the distribution of small size $\eta$ ' phases increases the strength ${ }^{15}$.

It is a known fact that there is a relation between strength/ hardness and temperatures of solution heat treatment and aging. The increase in the aging temperature reduces the yield strength ${ }^{22}$. Clark et al. ${ }^{23}$ study different solid solution temperatures of $420^{\circ} \mathrm{C}, 450^{\circ} \mathrm{C}, 480^{\circ} \mathrm{C}, 510^{\circ} \mathrm{C}$, and $530^{\circ} \mathrm{C}$ and different artificial aging temperatures of $107^{\circ} \mathrm{C}, 121^{\circ} \mathrm{C}$, and $165^{\circ} \mathrm{C}$ for AA7075. They analyze and evaluate the effective parameters. Distribution of $M g Z n_{2}$ phase is seen as a result of those steps ${ }^{9}$. If cooling is performed rapidly, $M g Z n_{2}$ phase distributions do not occur since there is not enough time for precipitation of $\mathrm{Mg}$ and $\mathrm{Zn}$ atoms ${ }^{6,9}$. The $\mathrm{MgZn}$, phase starts to appear after $150{ }^{\circ} \mathrm{C}$ temperature and the phase distributions increase as the temperature increases. In the precipitation section of aging, GP, $\eta$ ', $\eta$ ', and $\eta$ phases may be seen in the microstructure. However, strength loss is considerable after $150{ }^{\circ} \mathrm{C}^{24} . \eta$ ' phase has the best strength value ${ }^{25,26} . \eta$ phase occurs in the case of over-aging but it reduces the strength ${ }^{26,27}$. $\eta$ 'phase occurrences decrease above $190{ }^{\circ} \mathrm{C}{ }^{15}$. At $145^{\circ} \mathrm{C}$, $165^{\circ} \mathrm{C}$, and $185^{\circ} \mathrm{C}$, both $\eta$ ' and $\eta$ are seen, mostly $\eta{ }^{\prime 28}$.
In addition to the material properties, springback is also decreased with increasing aging temperature and time (duration) ${ }^{29}$.

The term of Portevin-Le Chatelier (PLC) effect is used as to define an unstable plastic flow behavioure that may be seen as fluctuations on stress strain curves during tensile tests. This effect occurs under certain regimes of strain rate and temperature. PLC effect may occure more than once on any locations along a specimen gauge length. Because the plastic strain may be localized and that localization causes degradation of the microstructure. Degradations effect surface quality of structural parts ${ }^{30}$.

In this study, the effects of aging temperatures, time, and pre-strain on mechanical properties of AA7075 are investigated. Studies in the literature show that GP zones start to take form in the microstructure around $120^{\circ} \mathrm{C}$. Solid precipitations start to be formed around $170{ }^{\circ} \mathrm{C}$, and precipitations start to change at elevated temperatures. Therefore, these values are chosen as aging temperatures. Additionally, the effect of duration and prestrain is investigated in this study. The study consists of material characterization, mechanical testing, and microstructural analysis. The originality of this study is to be comprehensive and to compare several factors on the aging process. The AA7075 material is very sensitive to temperature and aging time. So, some critical points need to be determined. For these aging parameters, precipitate formations in different aging conditions are shown by XRD method. Especially, the springback behaviors at different aging parameters have not been studied before.

\section{Material and Method}

A sheet of AA7075 material with $2 \mathrm{~mm}$ thickness was used in this study. The chemical composition of the material is given in Table 1.

The material was taken into dissolution at $500{ }^{\circ} \mathrm{C}$ for 2 hours. At the end of this operation, specimens were transferred into the water at room temperature (RT) within 10 seconds for quenching. The volume of quenching water was $1 \mathrm{~m}^{3}$. The specimens were immersed inside the quenching water for about 1 hour. Then, artificial aging temperatures of $120^{\circ} \mathrm{C}, 160$ ${ }^{\circ} \mathrm{C}$, and $200^{\circ} \mathrm{C}$ were chosen for aging times of $30,90,180,1080$, and 2880 minutes. A 4\% prestrain was applied to the specimens and tested. In fact, this pre-strain value corresponds the mean plastic deformation of body in white approximately during ovendrying. One of the aim of this study is to investigate the effect of paint baking process. Aging conditions are listed in Table 2.

Table 1. Chemical composition of AA7075 (in wt. \%)

\begin{tabular}{ccccccccc}
\hline $\mathrm{Si}$ & $\mathrm{Fe}$ & $\mathrm{Cu}$ & $\mathrm{Mn}$ & $\mathrm{Mg}$ & $\mathrm{Cr}$ & $\mathrm{Zn}$ & $\mathrm{Ti}$ & $\mathrm{Ti}+\mathrm{Zr}$ \\
\hline 0.07 & 0.12 & 1.5 & 0.02 & 2.6 & 0.18 & 5.8 & 0.05 & 0.08 \\
\hline
\end{tabular}

Table 2. Aging conditions of AA7075

\begin{tabular}{cccccc}
\hline \multirow{2}{*}{ Specimens } & \multirow{2}{*}{ Dissolution } & \multicolumn{2}{c}{ Quenching } & \multicolumn{2}{c}{ Artificial aging } \\
\cline { 3 - 5 } & & Coolant & Temp. $\left({ }^{\circ} \mathrm{C}\right)$ & Temperature $\left({ }^{\circ} \mathrm{C}\right)$ & Times $($ minutes $)$ \\
\hline $\begin{array}{l}\text { No pre-strained } \\
4 \% \text { pre-strained }\end{array}$ & $500{ }^{\circ} \mathrm{C}, 2$ hours. & Water & 25 & $120,160,200$ & $30,90,180,1080,2880$ \\
\hline
\end{tabular}


XRD tests are widely used to examine and classify atomic and molecular structure of materials. The XRD test is useful to determine the phases. Tthe area under peaks gives the ratios of phases. More information about materials is obtained by numerical methods applied to XRD graphics such as Rietveld's method ${ }^{31-36}$. Rietveld's method is based on the principle of curve fitting using a number of mathematical models. In the Rietveld's method, Gaussian, Lorentz, Voigt, etc. equations are used for curve fitting. Some numerical analysis programs applying Rietveld's method are MAUD (Material Analysis Using Diffraction) ${ }^{37}$, Profex (Rietveld Refinement) ${ }^{38}$ and FullProf Suite (Structure Profile Refinement) ${ }^{39}$. The MAUD program was used in this study. A Rietveld analysis was performed on graphics obtained from XRD tests of specimens.

In this study, the XRD tests were performed with a PANalytical XRD device between 30 to $90^{\circ}$ at the speed of 0.05 degree $/ \mathrm{min}$. The XRD device has a copper anode $\mathrm{XRD}$ tube which makes $\mathrm{CuK} \alpha$ radiation. XRD graphics are obtained to determine the presence of phases in the specimens.

For the metallographic processes, the samples were cold mounted by an epoxy filling material composed of UN3082 liquid resin and UN2259 triethylenetetramine hardener. For a good cold fixing, the ratio for hardener to resin was used as of $2 / 17$. Then grinding, polishing, and etching was conducted respectively. Struers Labopol-5 automatic polishing machine was used for these operations. In grinding process, sandpapers composed of $\mathrm{SiC}$ (silicon carbide) grain and magnetite dust were used in the order of 320, 500, 1200, 2400, and 4000 grids successively. To avoid any microstructural change, samples were cooled with water during the grinding process. In the polishing process, diamonds suspensions with different grain sizes and corresponding polishing fabrics suitable for the rotating discs were used by adjusting the amount of pressure on sample and rotation speed of the driving disc. During polishing, a smaller chip size is desirable to achieve a sample surface without scratches.
For this reason, the samples were then polished with 3-0.25 $\mu m$ diamond pastes to obtain a chip size approaching zero. It was taken into consideration that the grinding and the polishing time should be longer as the grain size of the grinding paper and polishing cloths decreases. In order to achieve a well-polished sample surface, a uniform contact had to be provided between sample surface and polishing fabric during polishing process. Different polishing suspensions with grain sizes such as $3 \mu \mathrm{m}, 1$ $\mu \mathrm{m}, 0.25 \mu \mathrm{m}$ and corresponding fabrics were used respectively. To adjust the moisture content and to wet, the fabric etchant was also used during polishing. Keller's reagent (1.0 mL HF, 1.5 mL HCl, $2.5 \mathrm{~mL} \mathrm{HNO}_{3}$, and $95.0 \mathrm{~mL} \mathrm{H}_{2} \mathrm{O}$ ) were used for etching. Etching was carried out for 8 seconds. The microstructure images were taken with the Olympus BX51 optical microscope which has lenses with magnifications $\mathrm{X} 5-\mathrm{X} 100$. On the micrographs taken byusing the X5, X10 and $\mathrm{X} 20$ lenses, the grains were not seen well because of the small magnification. The grains were not well focused and even one grain was too big to fit inside the image frame unfortunately when the X100 lens was used. So the lens with magnification $\mathrm{X} 50$ was chosen for the micrograph image in this study. Tensile and bending tests were performed on the aged specimens at a deformation speed of $25 \mathrm{~mm} / \mathrm{min}$. Vickers hardness (HV) of the samples was measured. Samples were loaded $10 \mathrm{~kg}$ during 15 seconds according to ASTM E92. The test specimens were cut by water jet in the rolling direction in the shape according to ASTM-E8 standard (Fig 2.a). A $60^{\circ} \mathrm{V}$-shaped bending die was used for the springback test as shown in Fig. 2.b. The experiments were carried out by a SHIMADZU Autograph AGS-X $100 \mathrm{kN}$ single axis tensile testing machine. Each test was repeated at least three times and averaged. The elongations and angles of the samples were measured with a video type extensometer. Springback tests were carried out by means of image processing techniques that measure angles before and after the bending process.

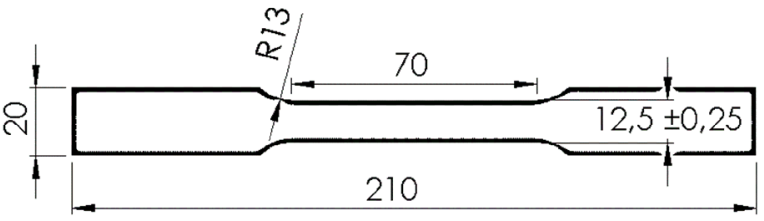

(a)

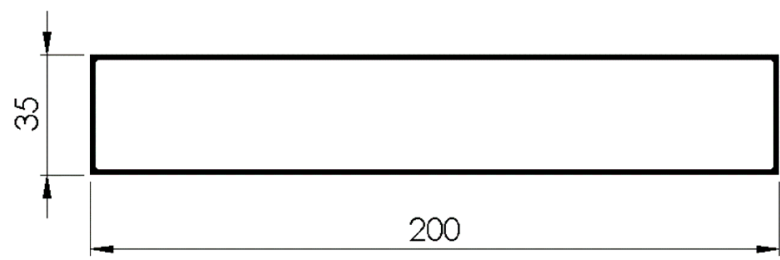

(b)

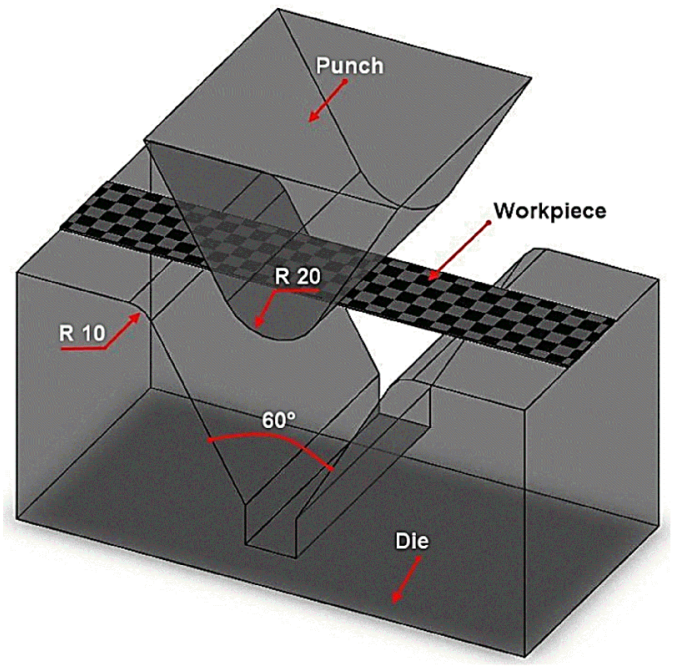

(c)

Figure 2. a) Tensile test, b) Bending test specimens, c) $60^{\circ} \mathrm{V}$-shaped bending test setup 
Hardness measurements were made by a Vickers hardness machine applying a $10 \mathrm{~kg}$ load for 15 seconds.

\section{Results and Discussion}

\subsection{XRD Analysis}

Samples with no pre-strain were examined. XRD results are shown in Fig. 3 - 7. It is a known fact that material properties are changed based on phases in microstructures.
These phases determine the material's characteristic properties, such as ductile or brittle behavior at failure. When a material is subjected to any deformation, the microstructure and therefore the XRD graph is changing. The XRD peaks shift to either the right or left side. This shift implies that internal stresses are formed in the material. The blue line in these graphs is called baseline, and the red line represents the peak of phases. Fig. 3 shows XRD results from specimens aged for 30 minutes at all different temperatures. The peaks obtained between $30-90^{\circ}$ scanning angles are seen in Fig. 3 (a).
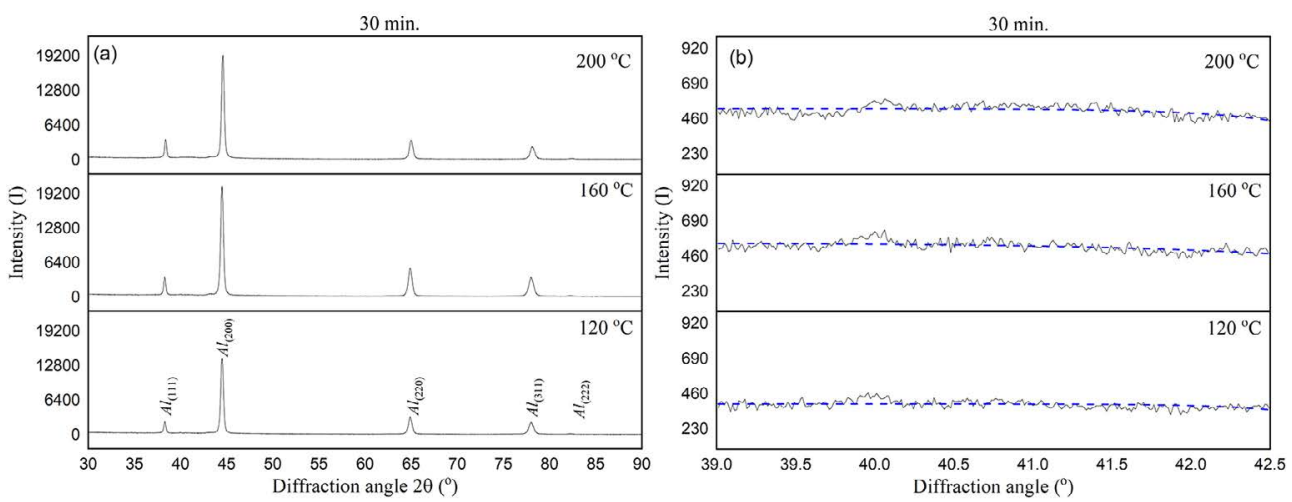

Figure 3. XRD results from samples aged for 30 minutes at different aging temperatures, a) Peaks obtained between $30-90^{\circ}$ scanning angles from specimens aged for 30 minutes. (Upper graphic is for aging at $200^{\circ} \mathrm{C}$. Graphic centered is at $160^{\circ} \mathrm{C}$. Lower graphic is at $\left.120^{\circ} \mathrm{C}\right)$, b) Zoomed image (39- 42.5 scanning angles)
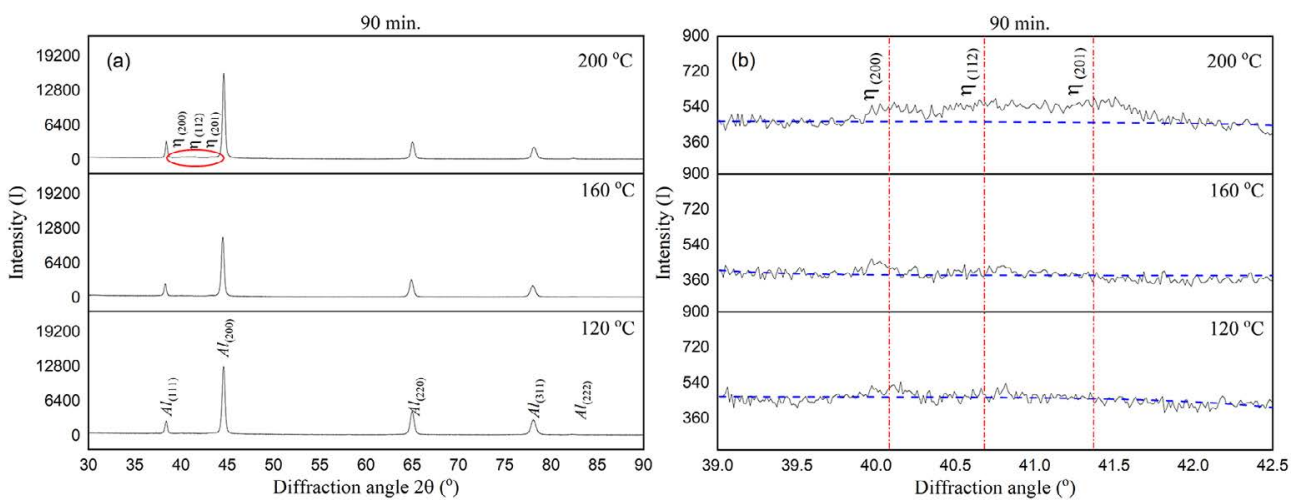

Figure 4. XRD results from samples aged for 90 minutes at different aging temperatures, a) Peaks obtained between 30- $90^{\circ}$ scanning angles from specimens aged for 90 minutes, b) Zoomed image (39- 42.5 scanning angles)
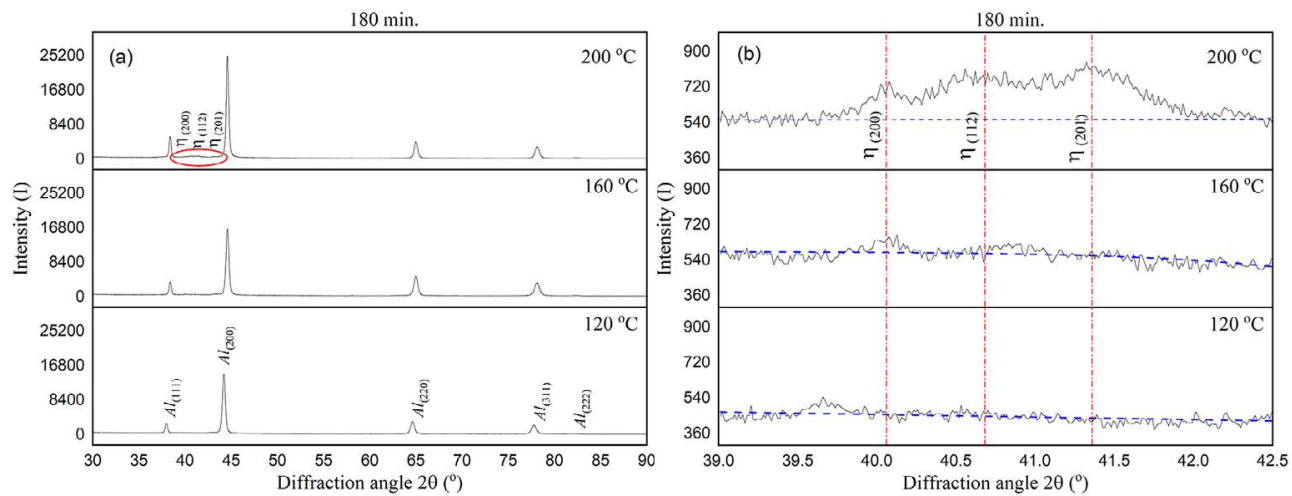

Figure 5. XRD results from samples aged for 180 minutes at different aging temperatures, a) Peaks obtained between $30-90^{\circ}$ scanning angles from specimens aged for 180 minutes, b) Zoomed image (39- 42.5 scanning angles) 

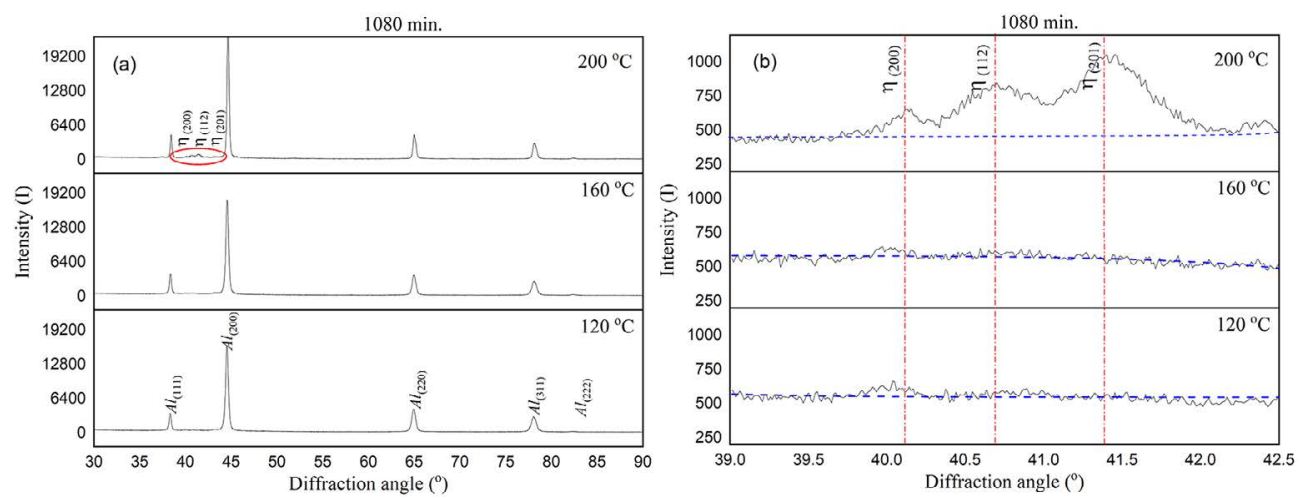

Figure 6. XRD results from samples aged for 1080 minutes at different aging temperatures, a) Peaks obtained between $30-90^{\circ}$ scanning angles from specimens aged for 1080 minutes, b) Zoomed image (39- 42.5 scanning angles)
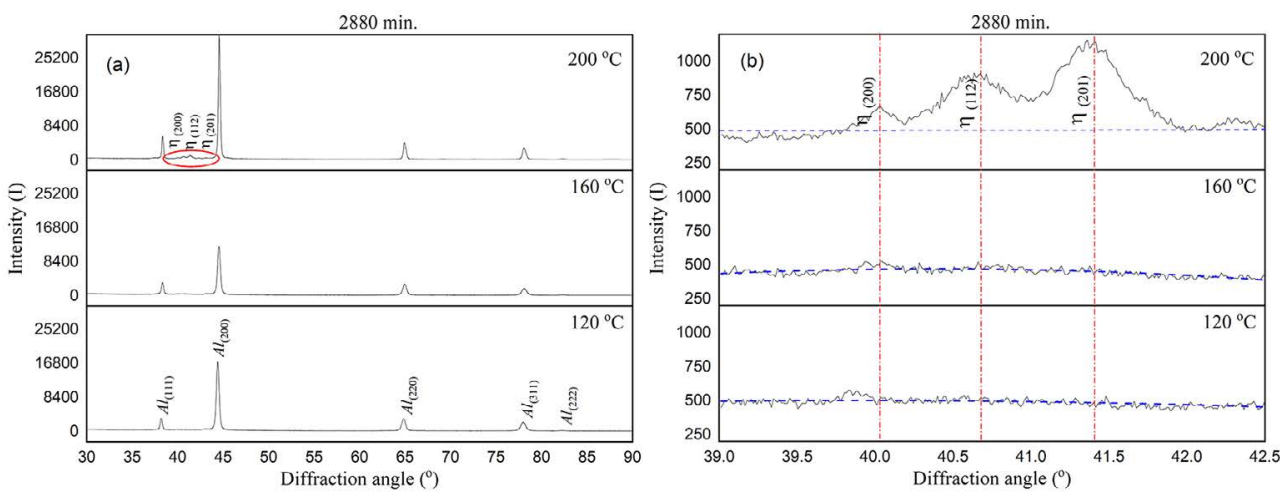

Figure 7. XRD results from samples aged for 2880 minutes at different aging temperatures, a) Peaks obtained between $30-90^{\circ}$ scanning angles from specimens aged for 2880 minutes, b) Zoomed image (39- 42.5 scanning angles)

Its zoomed section is given in Fig. 3 (b). Based on the peaks on the graphic, it is proven that the microstructure consists of $\mathrm{Al}$ and $\mathrm{MgZn}$, phases as reported in references of ${ }^{40,41}$. For 30 minutes aging time, no $M g Z n$, phase was observed at all aging temperatures $\left(120,160\right.$, and $\left.200{ }^{\circ} \mathrm{C}\right)$ as displayed in Fig. 3 (b). The main reason was that the time was too short to form a phase. After 90 minutes, $M g Z n_{2}$ phase was formed gradually as seen in Fig. 4. With increasing aging time, $M g Z n_{2}$ phase was continued to increase in volume (Fig 5-7). However, the amount of phase in total volume was less than 3\%. All these graphs reveal that the increase in aging time results in $M g Z n_{2}$ increase.

\subsection{Microstructural Analysis by Optical Microscopy}

Optical microscopy results of the samples obtained at elevated temperatures and aging durations are displayed in Fig. 8 taken from samples without pre-strain. It can be seen from the figures that the artificial aging has little influence on the grain size as expected. To be able to see grains and their boundaries, samples are etched using macro etching solution. No cracks/grooves are observed. No twins are seen. Grains have equiaxed shape in any direction. Line intercept length method is used (in accordance with the recommendations of ASTM E1382) for grain size determination. Size measurements are performed on each line and averaged as seen in Table 3.

Table 3. Grain size measurements and standard deviations

\begin{tabular}{|c|c|c|c|c|c|c|c|}
\hline \multirow{3}{*}{ Grain orientation } & \multirow{3}{*}{ Aging Temp. $\left({ }^{\circ} \mathrm{C}\right)$} & \multicolumn{6}{|c|}{ Grain size $(\mu \mathrm{m})$} \\
\hline & & \multicolumn{6}{|c|}{ Aging time (min.) } \\
\hline & & 30 & 90 & 180 & 1080 & 2880 & Mean \\
\hline \multirow{3}{*}{ 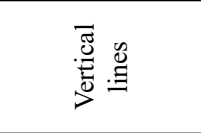 } & 120 & $121.21 \pm 9.54$ & $115.34 \pm 6.65$ & $143.57 \pm 2.66$ & $155.82 \pm 5.49$ & $130.46 \pm 8.29$ & 133.28 \\
\hline & 160 & $102.27 \pm 8.55$ & $149.82 \pm 8.02$ & $98.99 \pm 10.03$ & $101.14 \pm 5.51$ & $95.43 \pm 0.52$ & 109.53 \\
\hline & 200 & $89.93 \pm 11.56$ & $91.85 \pm 5.15$ & $174.71 \pm 12.16$ & $81.22 \pm 4.97$ & $44.78 \pm 2.13$ & 96.50 \\
\hline \multirow{3}{*}{ 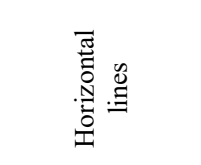 } & 120 & $111.64 \pm 10.49$ & $121.21 \pm 4.43$ & $138.58 \pm 3.29$ & $154.78 \pm 7.42$ & $128.92 \pm 9.57$ & 131.03 \\
\hline & 160 & $113.54 \pm 10.51$ & $150.52 \pm 4.29$ & $105.44 \pm 8.52$ & $100.62 \pm 5.86$ & $96.36 \pm 8.69$ & 113.30 \\
\hline & 200 & $91.66 \pm 12.97$ & $90.35 \pm 6.52$ & $155.76 \pm 9.13$ & $80.74 \pm 5.82$ & $53.67 \pm 12.71$ & 94.44 \\
\hline
\end{tabular}



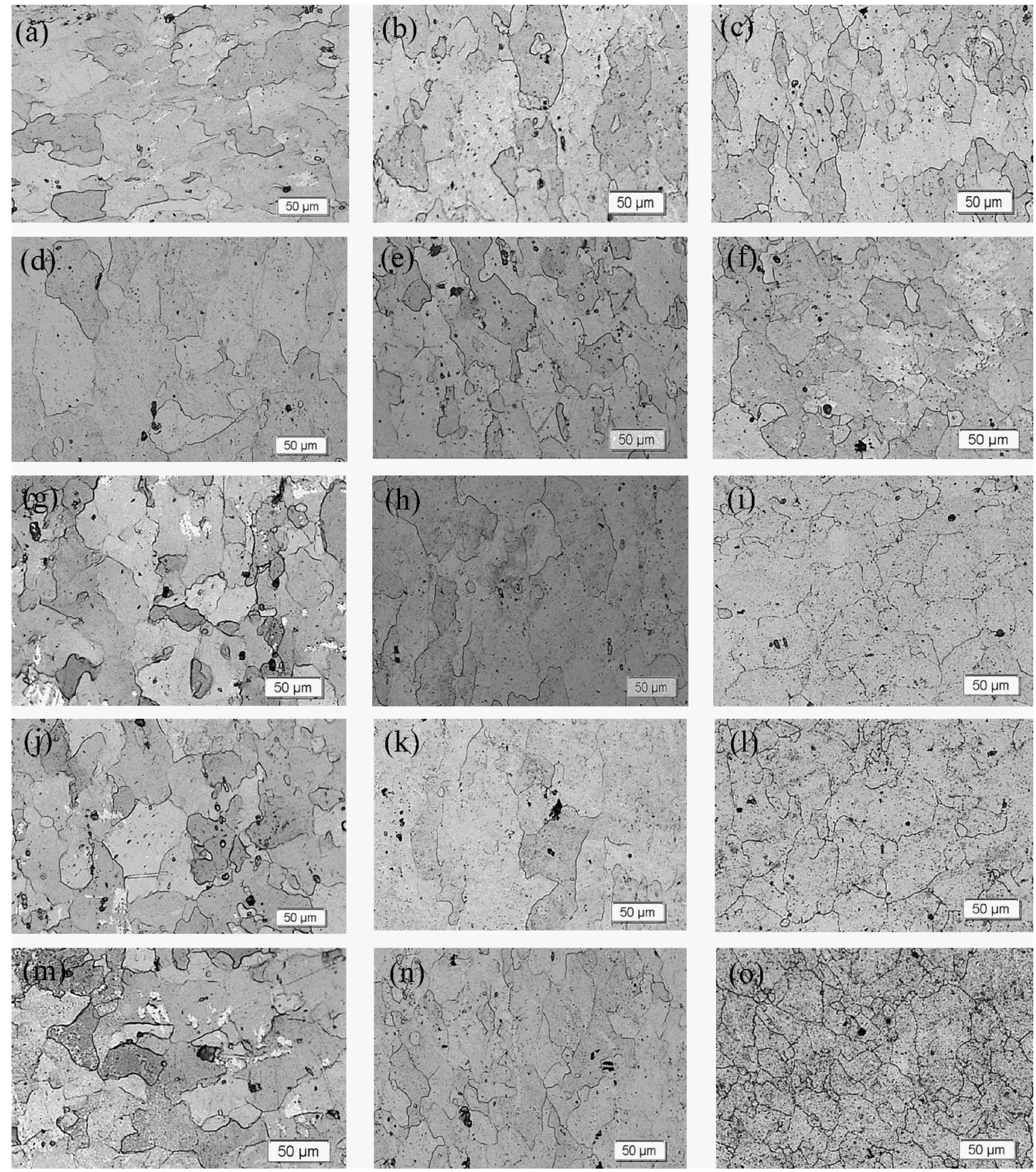

Figure 8. Microstructures obtained at different aging temperatures and time, a) $120^{\circ} \mathrm{C}-30 \mathrm{~min}$., b) $160^{\circ} \mathrm{C}-30$ minute, c) $200^{\circ} \mathrm{C}-30$ minute, d) $120^{\circ} \mathrm{C}-90$ minute, e) $160{ }^{\circ} \mathrm{C}-90$ minute, f) $200^{\circ} \mathrm{C}-90$ minute, g) $120^{\circ} \mathrm{C}-180$ minute, h) $160{ }^{\circ} \mathrm{C}-180$ minute, i) $200{ }^{\circ} \mathrm{C}-180$ minute, j) $120^{\circ} \mathrm{C}$ -1080 minute, k) $160{ }^{\circ} \mathrm{C}-1080$ minute, 1) $200^{\circ} \mathrm{C}-1080$ minute, m) $120^{\circ} \mathrm{C}-2880$ minute, n) $160{ }^{\circ} \mathrm{C}-2880$ minute, o) $200{ }^{\circ} \mathrm{C}-2880$ minute

Just two orientations as $0^{\circ}$ and $90^{\circ}$ are used for size analysis to investigate whether grains are elongated at transverse and lateral directions. Any noticeable grain elongation is not observed at both directions. However, change of grain size is significant.

Observations revealed that the mean grain size decreases at elevated temperatures from $130 \mu \mathrm{m}$ up to $90 \mu \mathrm{m}$ when duration time is $30 \mathrm{~min}$ and $90 \mathrm{~min}$. When duration time is 180,1080 , and $2880 \mathrm{~min}$., images show additional smaller sized grains.
Their mean size is $20 \mu \mathrm{m}$. When duration time is $200^{\circ} \mathrm{C}$ and evaluated together with XRD results, it can be concluded that those smaller sized phases are $\mu$ phases responsible for softer structure causing easier deformability. But smaller-sized grains are not seen up to $160^{\circ} \mathrm{C}$ when $30 \mathrm{~min}$. duration time. They have homogeneous distribution inside main $\mathrm{Al}$ matrix.

The $\eta$ phase is located in large precipitates (diameter $>$ $50 \mu \mathrm{m}$ ) and on grain boundaries that can be seen just by TEM (transmission electron microscope). In this study, 
TEM analysis was not done, however, the TEM photographs of these phases can be seen in that reference ${ }^{42}$. Optical microscope photographs were provided here to give general overview about the microstructures. All these graphs indicate that grain sizes are changed with increasing temperature. Grain sizes at the different aging time are different and changed with increasing time. Grain visibility is gradually increased with increasing aging time.

\subsection{Tensile Tests}

Summary of tensile test results is shown in Fig. 9 - 11. Fig. 9 indicates that the stress increases with increasing aging time. Similar behavior is observed in the case where the aging temperature is $160^{\circ} \mathrm{C}$ as seen in Fig. 10. When aging temperature is $200^{\circ} \mathrm{C}$, the stress decreases with increasing aging time, unlike other aging tests at lower temperatures. The material behavior is completely opposite at higher aging temperature. The main reason is that the $M g Z n_{2}$ precipitates which start to occur in microstructure as depicted in Fig. 4 - 7.

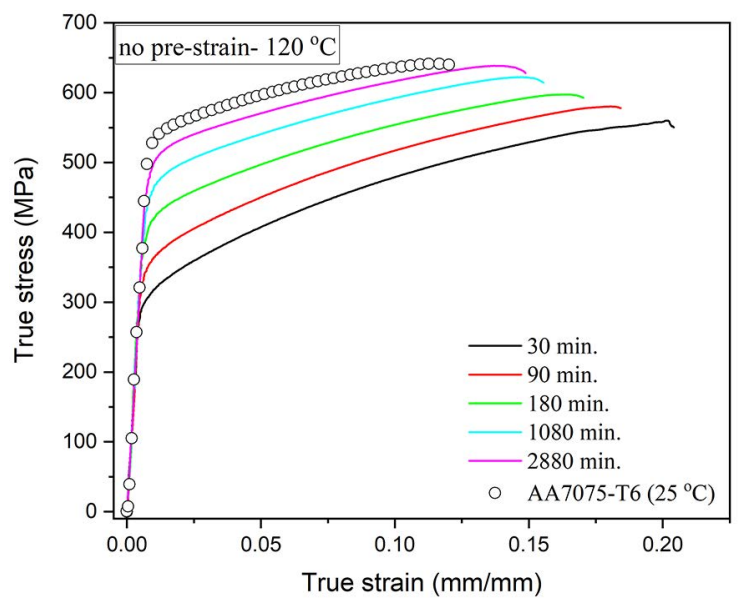

Figure 9. True stress vs. true strain for different aging time at $120^{\circ} \mathrm{C}$ (no pre-strain)

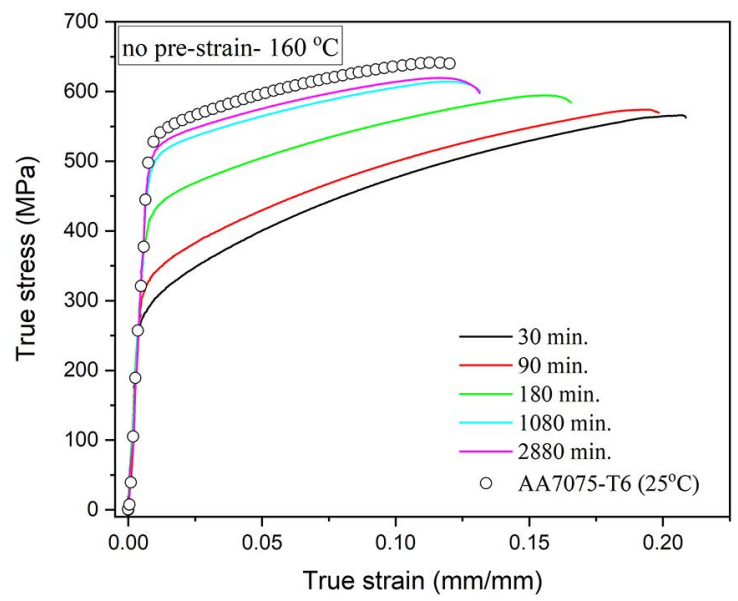

Figure 10. True stress vs. true strain for different aging time at $160{ }^{\circ} \mathrm{C}$ (no pre-strain)

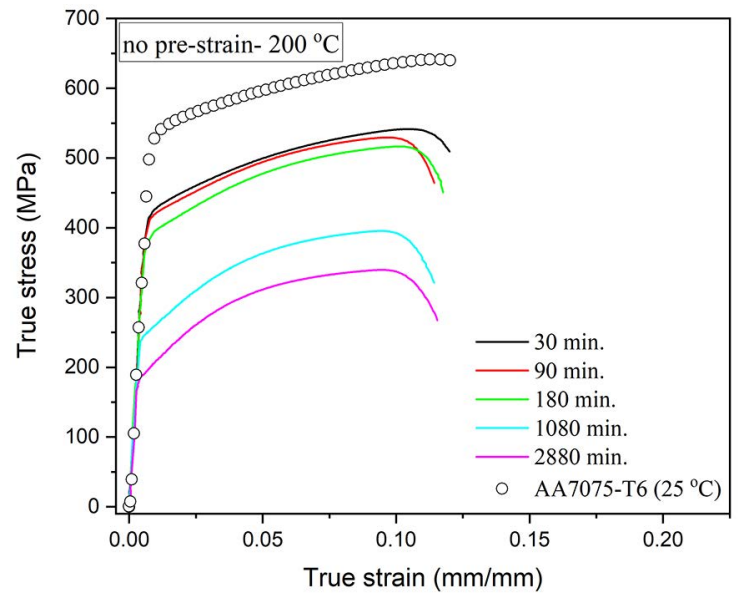

Figure 11. True stress vs. true strain for different aging time at $200{ }^{\circ} \mathrm{C}$ (no pre-strain)

Similar tests were done for the $4 \%$ pre-strain condition. The graphs are shown in Fig. 12 - 14. At aging temperatures of 120 and $160^{\circ} \mathrm{C}$, the true stress increases and the true strain decreases with increasing aging time. At these temperatures, Portevin-Le Chatelier effect was observed for aging durations of 30 and 90 minutes. This effect was also slightly observed at 180 minutes aging. In the case of higher aging time, this effect was disappeared. At an aging temperature of 200 ${ }^{\circ} \mathrm{C}$, the stress was decreased with increasing aging time. This was also due to the formation of $M g Z n_{2}$ precipitates in microstructure as depicted in Fig. 7.

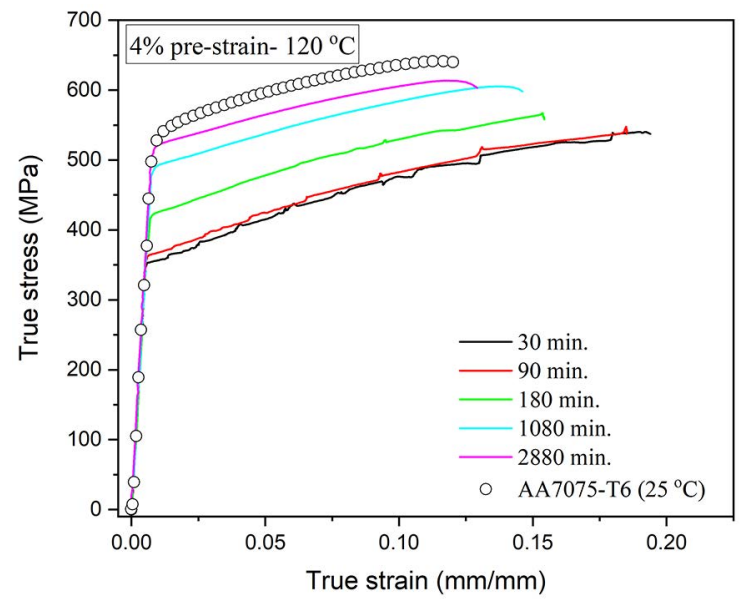

Figure 12. True stress vs. true strain for different aging time at $120{ }^{\circ} \mathrm{C}(4 \%$ pre-strain)

It is well known that yield strength decreases due to lack of strain hardening resulted from the accumulation of dislocation density and dislocation pile-ups ${ }^{15}$. It can be seen that dislocations dissolved at $200^{\circ} \mathrm{C}$ as expected.

Comparisons of material properties for pre-strained and no pre-strained cases are shown in Fig. 15 - 17. 


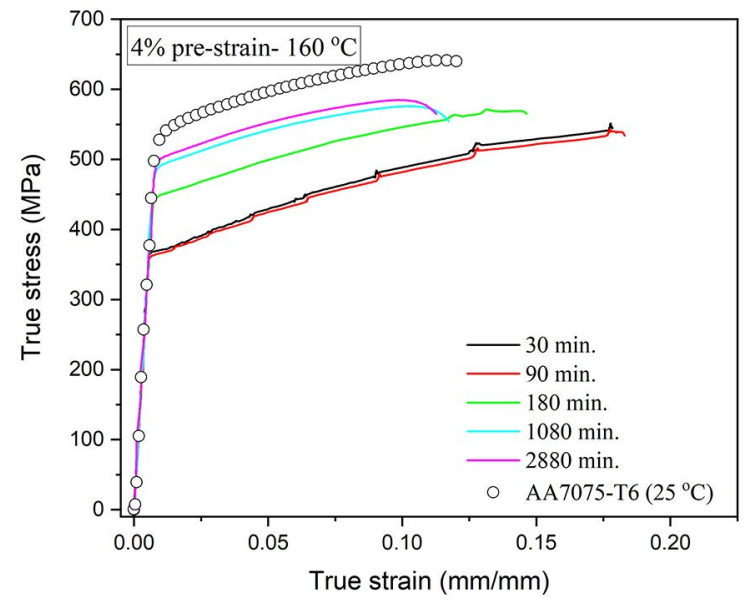

Figure 13. True stress vs. true strain for different aging time at $160{ }^{\circ} \mathrm{C}(4 \%$ pre-strain $)$

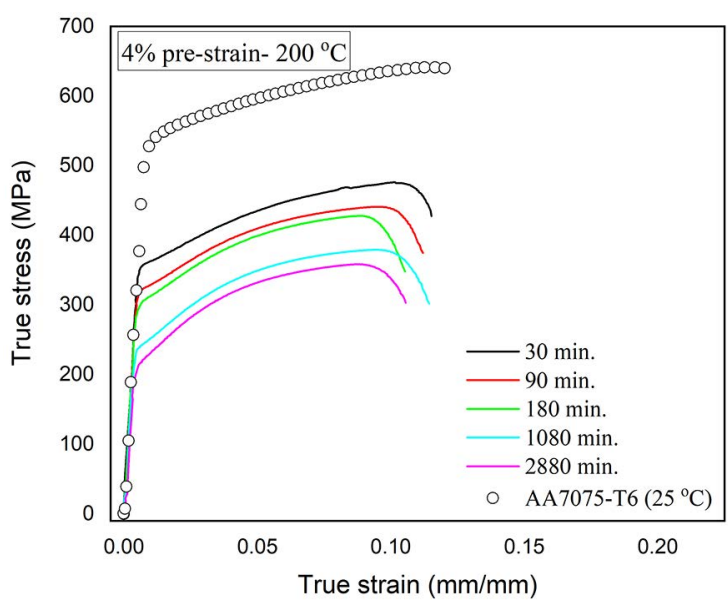

Figure 14. True stress vs. true strain for different aging time at $200{ }^{\circ} \mathrm{C}$ (4\% pre-strain)

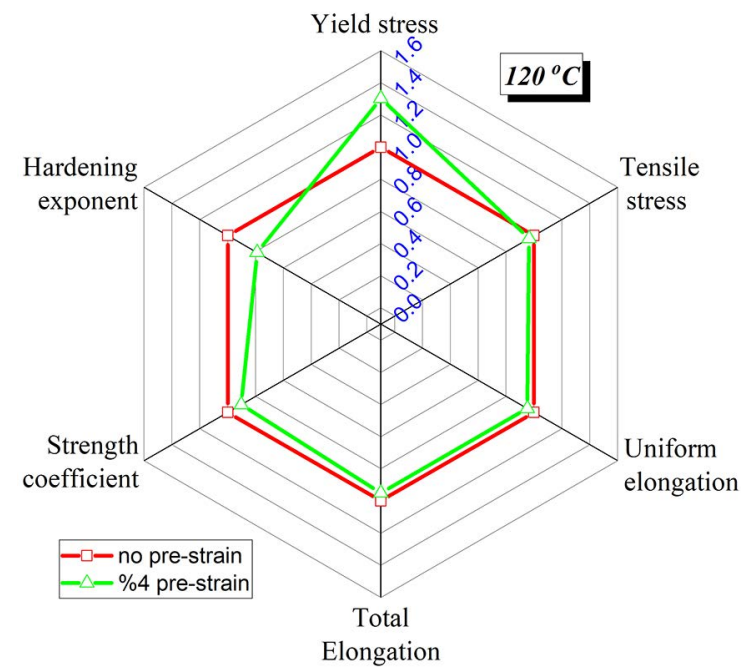

Figure 15. Comparison of mechanical properties at $120{ }^{\circ} \mathrm{C}$

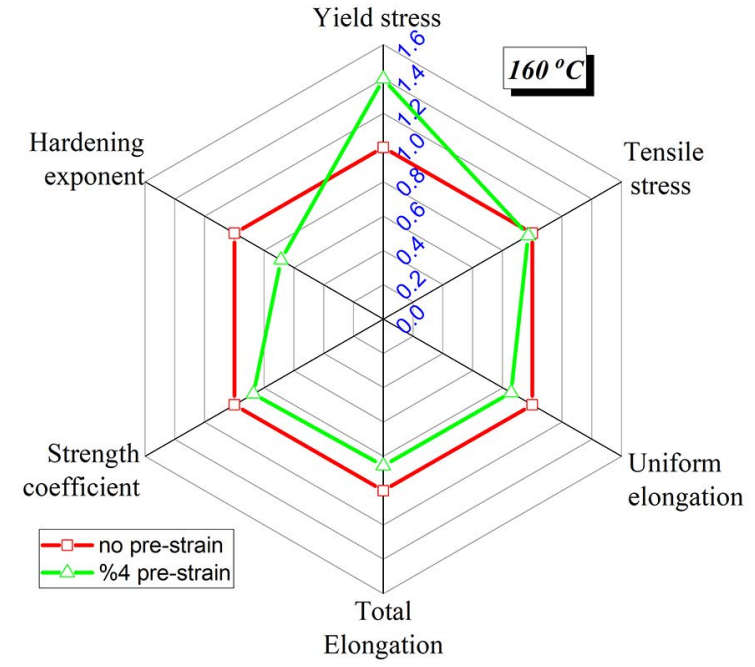

Figure 16. Comparison of mechanical properties at $160{ }^{\circ} \mathrm{C}$

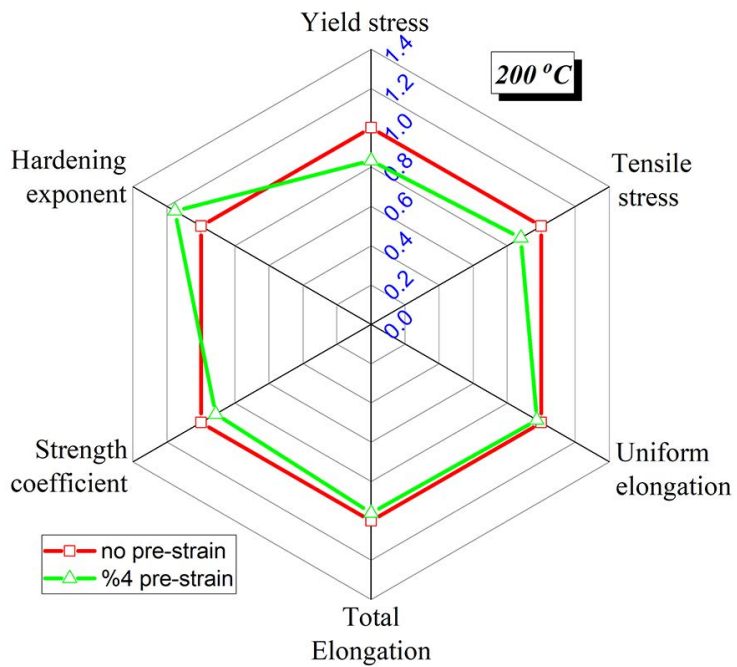

Figure 17. Comparison of mechanical properties at $200{ }^{\circ} \mathrm{C}$

In the cases of 120 and $160{ }^{\circ} \mathrm{C}$ aging temperatures, the yield stress increased, while other properties had a slight decrease with the pre-strain. At the $200{ }^{\circ} \mathrm{C}$ aging temperature, all values except for the strain-hardening exponent decreased.

Table 4. shows the change of tensile strength and standard deviations.

\subsection{Springback tests}

Aging duration is an affective parameter on springback. At aging temperatures of 120 and $160{ }^{\circ} \mathrm{C}$, the amount of springback increased with increasing aging time and decreased at $200{ }^{\circ} \mathrm{C}$ as illustrated in Fig. 18 for no pre-strain case. The amount of springback according to the aging duration for samples with $4 \%$ pre-strain is given in Fig. 19. It is clear that the behavior is similar to the case without pre-strain. However, the graphs are shifted to the left side (intersection point). 


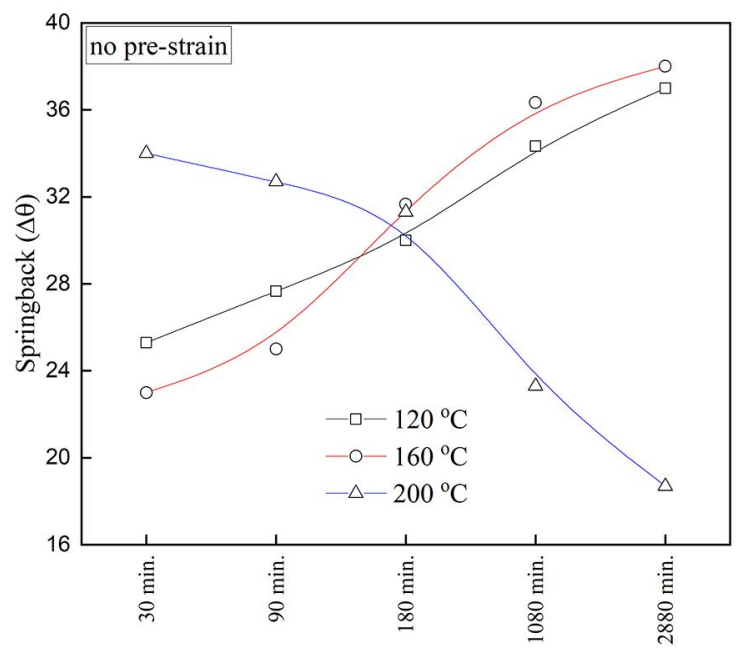

Figure 18. Effects of different aging temperatures and time on springback (no pre-strain)

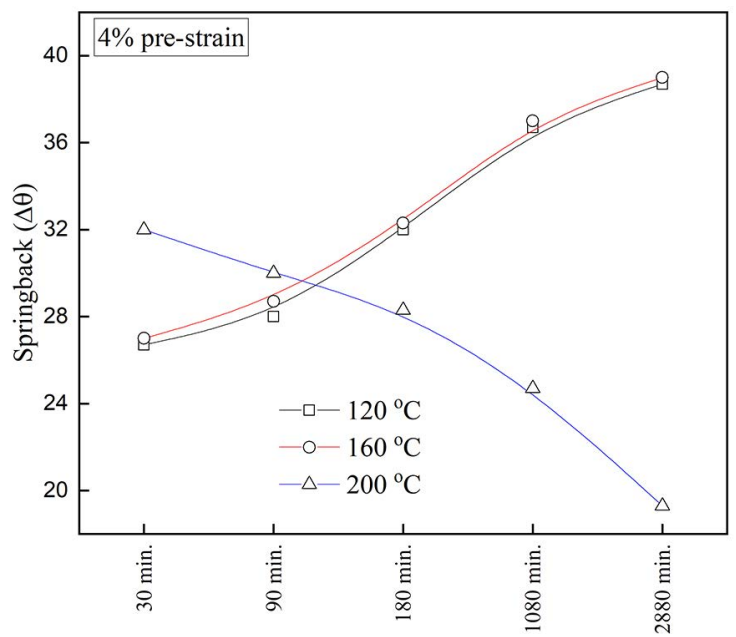

Figure 19. Effects of different aging temperatures and time on springback ( $4 \%$ pre-strain)

One of the parameters affecting the amount of springback is yield stress. As shown in Fig. 9 - 11, at elevated temperatures yield stress decreased. Similarly, springback decreased too as shown in Fig. 18, 19.

\subsection{Hardness Measurement}

Vickers hardness results of the samples are shown in Fig. 20. The hardness of the AA7075-T6 alloy is around 180 (HV). It is seen that the hardness values with increasing time at 120 and $160^{\circ} \mathrm{C}$ aging temperatures approach to T6 hardness value. Hovewer, at $200{ }^{\circ} \mathrm{C}$, hardness decreases catastrophically.

There is a relation between yield stress and hardness ${ }^{29}$. When Fig 20 is evaluated together with Fig 9-11, it will be seen that as the yield stress increases, the hardness and the springback increase too.

\subsection{Straightening Curves}

Straightening curves are drawn by ultimate tensile strength vs. aging time. When the relationship between two variables is not a straight line, the graph of the variables will help the designer to select suitable aging time easily. These curves are commonly used for a new heating sequence design in the cases having any precipitation-hardening mechanisms. This curve exhibits required process parameters to be able to obtain peak hardness/strength values. It presents a powerful comparison opportunity by including just ultimate tensile strength values corresponding different aging durations.

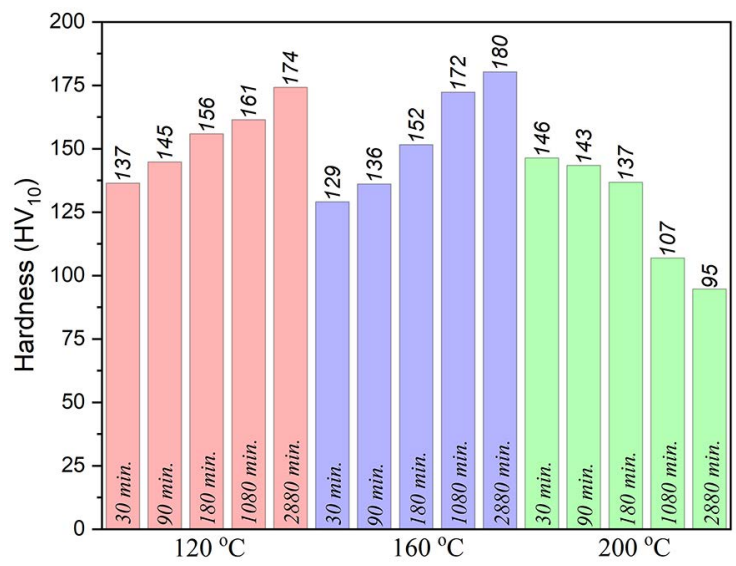

Figure 20. Effect of different aging temperatures and time on hardness

Table 4. Change in tensile strength

\begin{tabular}{|c|c|c|c|c|c|c|}
\hline \multicolumn{2}{|r|}{ Condition } & \multicolumn{5}{|c|}{ Ultimate tensile strength $(\mathrm{MPa})$} \\
\hline & \multirow{2}{*}{ Aging Temp. $\left({ }^{\circ} \mathrm{C}\right)$} & \multicolumn{5}{|c|}{ Aging time (min.) } \\
\hline & & 30 & 90 & 180 & 1080 & 2880 \\
\hline \multirow{3}{*}{ 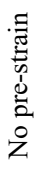 } & 120 & $565.35 \pm 6.54$ & $578.27 \pm 2.84$ & $598.16 \pm 6.73$ & $628.84 \pm 6.65$ & $639.60 \pm 1.02$ \\
\hline & 160 & $565.33 \pm 2.95$ & $574.45 \pm 4.21$ & $597.72 \pm 8.01$ & $612.13 \pm 5.02$ & $618.64 \pm 6.94$ \\
\hline & 200 & $540.39 \pm 2.24$ & $529.53 \pm 3.43$ & $514.63 \pm 5.87$ & $396.17 \pm 5.15$ & $342.51 \pm 3.31$ \\
\hline \multirow{3}{*}{ 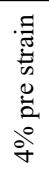 } & 120 & $533.84 \pm 5.49$ & $543.09 \pm 8.29$ & $566.92 \pm 5.83$ & $606.79 \pm 1.42$ & $615.35 \pm 6.57$ \\
\hline & 160 & $549.20 \pm 5.51$ & $543.06 \pm 0.52$ & $573.96 \pm 2.22$ & $577.46 \pm 10.86$ & $583.17 \pm 3.69$ \\
\hline & 200 & $482.04 \pm 4.97$ & $443.47 \pm 2.13$ & $432.20 \pm 4.78$ & $379.05 \pm 0.82$ & $351.99 \pm 5.71$ \\
\hline
\end{tabular}


Peak strength usually is being achieved after GP zones where coherency is maximum between precipitates. After the peak, coherency decreases because the particle grows to a critical size. Fig. 21 gives two straightening curves. As seen, while the maximum strength is obtained at 2880 minutes for 120 and $160{ }^{\circ} \mathrm{C}$ aging temperatures, strength decreases after 30 minutes at $200{ }^{\circ} \mathrm{C}$.
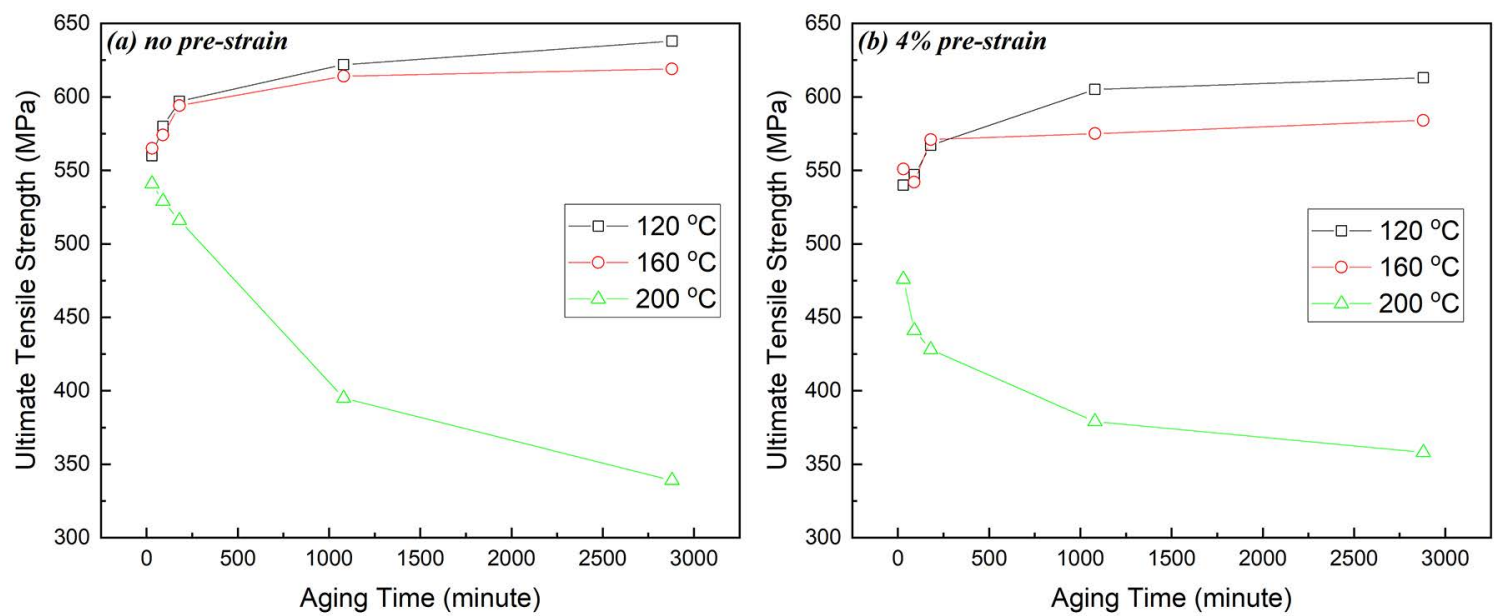

Figure 21. Correlation of strength and aging time for different temperatures for, a) specimens without pre strain, b) specimens with $4 \%$ pre strain

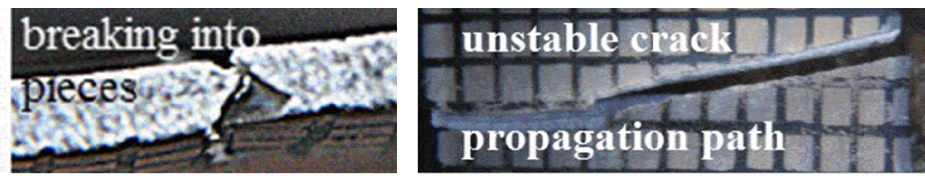

(a)

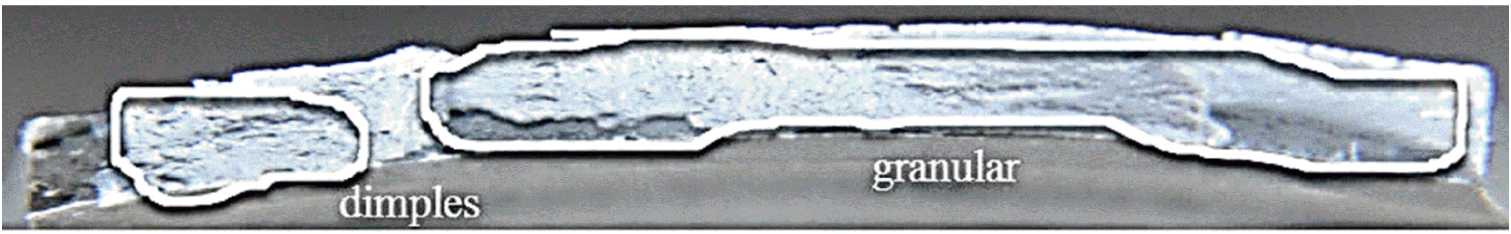

(b)
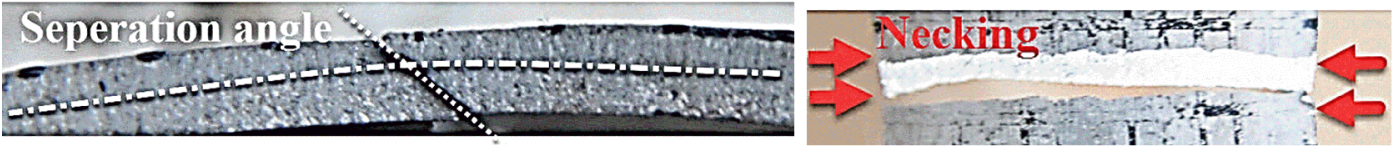

(c)

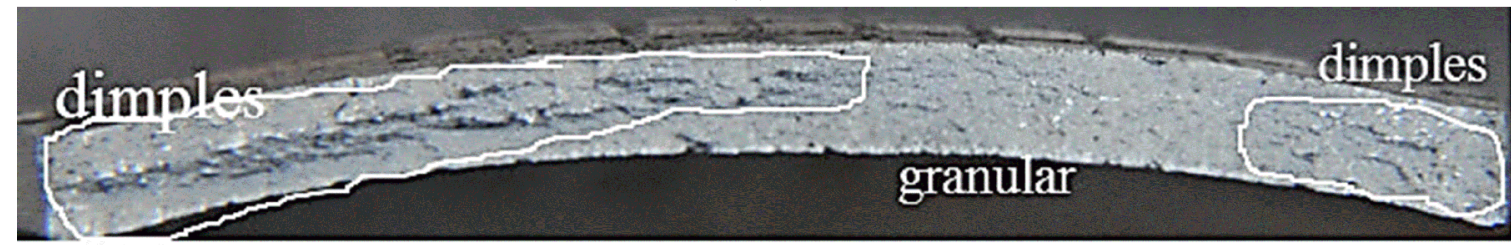

(d)

Figure 22. Photographs of fracture surfaces, a) Crack propagation path of AA7075-T6, side and front of sample, b) Cross section of ruptured surface of AA7075-T6, c) Crack propagation path of AA7075, dissolved at $500{ }^{\circ} \mathrm{C}$, side and front of sample, d) Cross section of ruptured surface of AA7075, dissolved at $500^{\circ} \mathrm{C}$ 
In the overall appearance of the surface's cross sections, both granular face and dimples are clearly visible because of typical crack propagation from one side to other side. By tracing back the crack sideview path, it can be seen that when the crack follows a straight path for AA7075 T6, sample is split off by following a $45^{\circ}$ path with lateral necking for AA7075 dissolved at $500{ }^{\circ} \mathrm{C}$. It is a sign that the cleavagelike fracture is predominated throughout section for AA7075 T6. Area including dimples is smaller than that of cleavage zone. The cleavage zones of fracture surface exhibit a rough, dull appearance with coarse grainy morphology and bright appearance due to the reflectivity of cleaved crystals. It is commonly an evidence for overstress failures. The cleavage zone points out fast fracture. It is seen that while AA7075 with T6 temper is exposed to brittle fracture, the samples dissolved exhibit ductile failures.

While Vickers hardness value of AA7075 T6 is measured as $185 \mathrm{HV}$, it is $155 \mathrm{HV}$ for the samples dissolved at 500 . The sample in which the brittle fracture is observed is the sample with a high hardness value.

\section{Conclusions}

In this study, the effects of aging temperature, time, and pre-strain on mechanical properties are examined for AA7075. The main conclusions obtained from the investigations are as follows:

$M g Z n_{2}$ precipitation is not observed at aging temperatures of 120 and $160{ }^{\circ} \mathrm{C}$. At $200{ }^{\circ} \mathrm{C}, M g Z n$, precipitate begins to be formed after 30 minutes of aging time and the amount of precipitation increases with increasing time. It is seen that the distribution of $M g Z n_{2}$ dispersions increases the strength.

When aging continued at a higher temperature or longer time period after the formation of $M g Z n_{2}$ precipitates, microstructure becomes softer. The reason is that when the precipitate size exceeds a critical value, it makes the dislocation movements easy and causes the strength to decrease. The phase change using Rietveld analysis is shown.

The increase in the aging temperature reduces the yield stress value.

Pre-strain causes Portevin-Le Chatelier effect at the aging temperatures of 120 and $160{ }^{\circ} \mathrm{C}$ for 30 and 90 minutes of aging times whereas this effect is disappeared at the longer aging time.

It is seen that while AA7075 with T6 temper is exposed to brittle fracture, the dissolved samples exhibit ductile fail. The sample in which the brittle fracture is observed is the sample with a high hardness value.

Paint baking operation usually takes 10-30 minutes at $120{ }^{\circ} \mathrm{C}$. For this material, it is seen that these durations are insufficient, and the paint baking durations should be kept longer.
The hardness at $160{ }^{\circ} \mathrm{C}, 2880 \mathrm{~min}$. is $89.8 \%$ bigger than that of other aging conditions and is the same as the hardness of AA7075 T6. Similarly, 86.4\% is the highest difference on ultimate tensile strengths and seen at $120{ }^{\circ} \mathrm{C}$, $2880 \mathrm{~min}$. Pre-strain leads yield strength to decrease for all aging conditions. Any improvement on yield strength obtained from aged samples is not seen when compared to that of AA7075 T6.

In industry, the main challenge is to be able to overcome the deformation defects. The optimum deformation can be obtained with minimum springback and maximum elongation. It is concluded that when duration time for artificial aging is $30 \mathrm{~min}$ at $160^{\circ} \mathrm{C}$, the minimum springback is obtained. It leads a softer micro structure to be deformed easier and energy efficiently for complexshaped structural parts.

\section{Acknowledgment}

This work was supported by the Ahi Evran University Scientific Research Projects Coordination Unit. Project Number: MMF.A3.17.001. We would like to thank Scientific Research Projects Coordination Unit for their invaluable support.

\section{References}

1. Vasudevan AK, Doherty RD, eds. Aluminum Alloys-Contemporary Research and Applications: Contemporary Research and Applications. San Diego: Academic Press; 1989.

2. Yildirim M, Özyürek D, Gürü M. The Effects of Precipitate Size on the Hardness and Wear Behaviors of Aged 7075 Aluminum Alloys Produced by Powder Metallurgy Route. Arabian Journal for Science and Engineering. 2016;41(11):4273-4281.

3. Guner AT, Dispinar D, Tan E. Microstructural and Mechanical Evolution of Semisolid 7075 Al Alloy Produced by SIMA Process at Various Heat Treatment Parameters. Arabian Journal for Science and Engineering. 2019;44(2):1243-1253.

4. Mondal $\mathrm{C}$, Mukhopadhyay $\mathrm{AK}$. On the nature of $\mathrm{T}\left(\mathrm{Al}_{2} \mathrm{Mg}_{3} \mathrm{Zn}_{3}\right)$ and $\mathrm{S}\left(\mathrm{Al}_{-2} \mathrm{CuMg}\right)$ phases present in as-cast and annealed 7055 aluminum alloy. Materials Science and Engineering: $A$. 2005;391(1-2):367-376.

5. Lalpour A, Soltanipour A, Farmanesh K. Effect of Friction Stir Processing on the Microstructure and Superplasticity of 7075 Aluminum Alloy. In: $5^{\text {th }}$ International Biennial Conference on Ultrafine Grained and Nanostructured Materials (UFGNSM15); 2015 Nov 11-12; Tehran, Iran.

6. Fan XG, Jiang DM, Meng QC, Zhang BY, Tao W. Evolution of eutectic structures in $\mathrm{Al}-\mathrm{Zn}-\mathrm{Mg}-\mathrm{Cu}$ alloys during heat treatment. Transactions of Nonferrous Metals Society of China. 2006;16(3):577-581.

7. Lim ST, Eun IS, Nam SW. Control of Equilibrium Phases (M, $\mathrm{T}, \mathrm{S})$ in the Modified Aluminum Alloy 7175 for Thick Forging Applications. Materials Transactions. 2003;44(1):181-187. 
8. Binesh B, Aghaie-Khafri M. Phase Evolution and Mechanical Behavior of the Semi-Solid SIMA Processed 7075 Aluminum Alloy. Metals. 2016;6(3):42.

9. Isadare AD, Aremo B, Adeoye MO, Olawale OJ, Shittu MD. Effect of heat treatment on some mechanical properties of 7075 aluminium alloy. Materials Research. 2013;16(1):190-194.

10. Özyürek D, Yılmaz R, Kibar E. The effects of retrogression parameters in RRA treatment on tensile strength of 7075 aluminium alloys. Journal of the Faculty of Engineering and Architecture of Gazi University. 2012;27(1):193-203.

11. Polmear I. Recent developments in light alloys. Materials Transactions, JIM. 1996;37(1):12-31.

12. Hunsicker H. Development of Al-Zn-Mg-CU alloys for aircraft. Philosophical Transactions of the Royal Society of London. Series A, Mathematical and Physical Sciences. 1976;282(1):359-376.

13. Emani SV, Benedyk J, Nash P, Chen D. Double aging and thermomechanical heat treatment of AA7075 aluminum alloy extrusions. Journal of Materials Science. 2009;44(23):6384-6391.

14. Karaaslan A, Kaya I, Atapek H. Effect of aging temperature and of retrogression treatment time on the microstructure and mechanical properties of alloy AA 7075. Metal Science and Heat Treatment. 2007;49(9-10):443-447.

15. Park JK, Ardell AJ. Microstructures of the commercial $7075 \mathrm{Al}$ alloy in the T651 and T7 tempers. Metallurgical Transactions A. 1983;14(10):1957-1965.

16. Tash MM, Alkahtani S. Aging and Mechanical Behavior of Be-Treated 7075 Aluminum Alloys. International Journal of Materials and Metallurgical Engineering. 2014;8(3):252-256.

17. Joshi A, Shastry CR, Levy M. Effect of heat treatment on solute concentration at grain boundaries in 7075 Aluminum Alloy. Metallurgical Transactions A. 1981;12(6):1081-1088.

18. Özer G, Karaaslan A. Relationship of RRA heat treatment with exfoliation corrosion, electrical conductivity and microstructure of AA7075 alloy. Materials and Corrosion. 2017;68(11):1260-1267.

19. Ozer G, Karaaslan A. Properties of AA7075 aluminum alloy in aging and retrogression and reaging process. Transactions of Nonferrous Metals Society of China. 2017;27(11):2357-2362.

20. Viana F, Pinto AMP, Santos HMC, Lopes AB. Retrogression and re-ageing of 7075 aluminium alloy: microstructural characterization. Journal of Materials Processing Technology. 1999;92-93:54-59.

21. Fontana MG, Staehle RW. Advances in Corrosion Science and Technology. New York: Plenum Press; 1970.

22. Polmear IJ, Couper MJ. Design and development of an experimental wrought aluminum alloy for use at elevated temperatures. Metallurgical Transactions A. 1988;19(4):1027-1035.

23. Clark Jr R, Coughran B, Traina I, Hernandez A, Scheck T, Etuk $\mathrm{C}$, et al. On the correlation of mechanical and physical properties of 7075-T6 Al alloy. Engineering Failure Analysis. 2005;12(4):520-526.

24. Panigrahi SK, Jayaganthan R. Effect of Annealing on Thermal Stability, Precipitate Evolution, and Mechanical Properties of Cryorolled Al 7075 Alloy. Metallurgical and Materials Transactions A. 2011;42(10):3208-3217.
25. Park JK, Ardell AJ. Correlation between microstructure and calorimetric behavior of aluminum alloy 7075 and $\mathrm{Al} \mathrm{Zn} \mathrm{Mg}$ alloys in various tempers. Materials Science and Engineering: A. 1989;114:197-203.

26. Chen J, Zhen L, Yang S, Shao W, Dai S. Investigation of precipitation behavior and related hardening in AA 7055 aluminum alloy. Materials Science and Engineering: $A$. 2009;500(1-2):34-42.

27. Porter DA, Easterling KE, Sherif MY. Phase Transformations in Metals and Alloys. Boca Raton: CRC Press; 2009.

28. Mahathaninwong N, Plookphol T, Wannasin J, Wisutmethangoon S. T6 heat treatment of rheocasting $7075 \mathrm{Al}$ alloy. Materials Science and Engineering: A. 2012;532:91-99.

29. Arabi Jeshvaghani R, Emami M, Shahverdi HR, Hadavi SMM. Effects of time and temperature on the creep forming of 7075 aluminum alloy: Springback and mechanical properties. Materials Science and Engineering: A. 2011;528(29-30):87958799.

30. Yilmaz A. The Portevin-Le Chatelier effect: a review of experimental findings. Science and Technology of Advanced Materials. 2011;12(6):063001.

31. Moumeni H, Alleg S, Djebbari C, Bentayeb FZ, Grenèche JM. Synthesis and characterisation of nanostructured FeCo alloys. Journal of Materials Science. 2004;39(16-17):5441-5443.

32. Mehdaoui S, Benslim N, Assaouil O, Benabdeslem M, Bechiri $\mathrm{L}$, Otmani A, et al. Study of the properties of CuInSe ${ }_{2}$ materials prepared from nanoparticle powder. Materials Characterization. 2009;60(5):451-455.

33. Benslim N, Mehdaoui S, Aissaoul O, Benabdeslem M, Bouasla A, Bechiri L, et al. XRD and TEM characterizations of the mechanically alloyed $\mathrm{CuIn}_{05} \mathrm{Ga}_{05} \mathrm{Se}_{2}$ powders. Journal of Alloys and Compounds. 2010;489(2):437-440.

34. Dini G, Najafizadeh A, Monir-Vaghefi SM, Ueji R. Grain Size Effect on the Martensite Formation in a High-Manganese TWIP Steel by the Rietveld Method. Journal of Materials Science \& Technology. 2010;26(2):181-186.

35. Karpikhin AE, Fedotov AY, Komlev VS, Barinov SM, Sirotinkin VP, Gordeev AS, et al. Structure of hydroxyapatite powders prepared through dicalcium phosphate dihydrate hydrolysis. Inorganic Materials. 2016;52(2):170-175.

36. Heiba ZK, Mohamed MB, Wahba AM. Effect of Mo substitution on structural and magnetic properties of Zinc ferrite nanoparticles. Journal of Molecular Structure. 2016;1108:347-351.

37. Lutterotti L. Quantitative Rietveld analysis in batch mode with Maud. City; 2017.

38. Döbelin N, Kleeberg R. Profex: a graphical user interface for the Rietveld refinement program BGMN. Journal of Applied Crystallography. 2015;48(Pt 5):1573-1580.

39. Rodriguez-Carvajal J. Recent Developments of the Program FULLPROF. Commission on Powder Diffraction (IUCr) Newsletter; 2001;26:12-19

40. Pastor A, Svoboda HG. Time-evolution of Heat Affected Zone (HAZ) of Friction Stir Welds of AA7075-T651. Journal of Materials Physics and Chemistry. 2013;1(4):58-64. 
41. Oskouei RH, Barati MR, Ibrahim RN. Surface Characterizations of Fretting Fatigue Damage in Aluminum Alloy 7075-T6 Clamped Joints: The Beneficial role of Ni-P Coatings. Materials (Basel). 2016;9(3):E141.
42. Ma K, Wen H, Hu T, Topping TD, Isheim D, Seidman DN, et al. Mechanical behavior and strengthening mechanisms in ultrafine grain precipitation-strengthened aluminum alloy. Acta Materialia. 2014;62:141-155. 